\title{
Multi-antigen print immunoassay (MAPIA)-based evaluation of novel recombinant Leishmania infantum antigens for the serodiagnosis of canine visceral leishmaniasis
}

\author{
Isaac Queiroz de Oliveira', Rodrigo Araujo Silva ${ }^{1}$, Michel Vergne Sucupira ${ }^{2}$, Edmilson Domingos da Silva ${ }^{2}$, \\ Alexandre Barbosa Reis ${ }^{3,4}$, Gabriel Grimaldi $\mathrm{Jr}^{1}$, Deborah Bittencourt Mothé Fraga ${ }^{1,3,5}$ \\ and Patrícia Sampaio Tavares Veras ${ }^{1,3^{*}}$
}

\begin{abstract}
Background: Domestic dogs are the principal reservoir hosts of Leishmania infantum in regions where visceral leishmaniasis $(\mathrm{VL})$ is endemic. Although serologic methods are frequently used for the screening of infected dogs, antibody-based tests require further assessment, due to lack of sensitivity and specificity. In this study, we employed a multi-antigen printing immunoassay (MAPIA) to compare the antibody responses to novel recombinant proteins of $L$. infantum with the potential for the detection of canine VL.

Findings: MAPIA strips were prepared employing 12 recombinant proteins. Antibody reactivity to these antigens was compared using a panel of sera collected from clinically asymptomatic $(n=16)$ and symptomatic $(n=41)$ culture-positive animals. Our findings showed that the canine immune response to antigen differs between dogs and depends on infection status. Using this screening assay, when five out of the 12 antigens were combined, an overall $81 \%$ detection rate of $L$. infantum-infected dogs was achieved.
\end{abstract}

Conclusions: We conclude that MAPIA is an effective screening tool to rapidly select multiple antigens of diagnostic utility to be used in a more sensitive point of care diagnostic test such as the Dual-Path Platform (DPP) multiplex test for the rapid detection of infected dogs.

Keywords: MAPIA, Recombinant antigens, Leishmaniasis

\section{Background}

Zoonotic visceral leishmaniasis (VL) caused by L. infantum is an important emerging parasitic disease in many regions [1]. In the neotropics, L. infantum transmission to humans occurs as a result of Lutzomyia longipalpis bites [2]. Accordingly, dogs are the major source of $L$. infantum for humans; thus, early and accurate detection of infected dogs is critical to successfully controling the spread of leishmaniasis $[3,4]$. Additionally, it is also important to highlight the value of a reliable test to screen

\footnotetext{
* Correspondence: pveras@bahia.fiocruz.br

'Laboratório de Patologia e Biointervenção, Centro de Pesquisas Gonçalo Moniz, FIOCRUZ, Rua Waldemar Falcão, 121 (Candeal), Salvador, BA, Brazil ${ }^{3}$ Instituto de Ciência e Tecnologia de Doenças Tropicais, INCT-DT, Salvador, BA, Brazil

Full list of author information is available at the end of the article
}

seronegative dogs before vaccination and to confirm infection before culling of seropositive dogs.

Current parasitological diagnostic tests, including microscopic examination and in vitro culturing, offer limited sensitivity with respect to the direct detection of Leishmania. In addition, parasite-specific antibody tests, such as the immunofluorescent-antibody test [IFAT], direct agglutination test [DAT], enzyme-linked immunosorbent assay [ELISA], although widely used to diagnose infection, employ crude antigens derived from wholeparasite extracts and lack the appropriate sensitivity and specificity required for accurate serodiagnosis [5-11].

Recently, the use of recombinant protein-based immunochromatographic testing, such as lateral-flow and Dual-Path Platform (DPP ${ }^{\circ}$ ) technologies, has overcome 
the practical limitations of other serological-based methods in the field [6,11-13]. Previous studies have indicated the promising potential of antigen-based serodiagnostic assays for VL, employing a cocktail of antigens [14] or chimeric proteins [15] that cover a broad spectrum of immunoreactivities [16-19]. Although these tests perform well, they do have limitations; for example, $\mathrm{DPP}^{\circ}$ shows high sensitivity (98\%) and specificity (96\%) towards sera from symptomatic dogs, but shows a low sensitivity of only $47 \%$ towards sera from asymptomatic dogs [13].

With this in mind, we used the screening test, multiantigen print immunoassay (MAPIA), to further characterize antibody responses in order to select those $L$. infantum recombinant proteins with a greater capacity to be utilized for the serodiagnosis of canine visceral leishmaniasis (CVL). MAPIA is more efficient, cost-effective, and reproducible than other screening techniques. In addition, as MAPIA is a membrane-based assay, it can easily be developed into a rapid test that utilizes thin-layer immunochromatography, similar to rapid diagnostic tests for other infectious diseases [20]. This advantage is important because our future goal is to generate a more reliable DPP $^{\circ}$ assay [13], using MAPIA to carefully select multiple antigens for the effective serodiagnosis of $L$. infantum-infected dogs.

\section{Methods}

\section{Leishmania infantum antigens}

A set of 12 recombinant L. infantum antigens (rLci1A, rLci2B, rLci3, rLci4, rLci5, rLci6, rLci7, rLci8, rLci10, rLci11, rLci12, rLci13) was previously selected from DNA libraries based on antibody reactivity using sera from culture-positive dogs [21,22]. Histidine-tagged recombinant proteins were produced after sub-cloning DNA fragments as described previously [21]. The antigens were then purified by affinity chromatography using PD-10 Desalting Workmate nickel-sepharose columns (Amersham Pharmacia Biotech AB, Sweden), in accordance with the manufacturer's instructions.

\section{Dog sera and infection status}

A panel of 138 canine sera was used. Negative control sera were obtained from 40 kennel dogs from Pelotas, Rio Grande do Sul (a VL-free area of Brazil). These dogs tested negative for $L$. infantum via serology, culturing, and qPCR of splenic aspirate [23]. To test for crossreactivity of the 12 recombinant antigens with other pathogens, we also screened sera from dogs infected with Leishmania braziliensis $(\mathrm{n}=10)$, Trypanosoma cruzi $(\mathrm{n}=10)$, Babesia spp. $(\mathrm{n}=10)$, and Ehrlichia canis $(\mathrm{n}=11)$. To determine sensitivity, the antibody reactivity was assessed using a panel of 57 sera from symptomatic $(\mathrm{n}=41)$ and asymptomatic $(\mathrm{n}=16)$ culture-positive dogs. All infected dogs enrolled in the study were selected during epidemiological surveys of CVL carried out in four endemic areas in Brazil: Camaçari, Bahia; Dias D’Àvila, Bahia; Jequié, Bahia; and Pancas, Espírito Santo. At the time of sampling, dogs were clinically examined for seven typical signs of CVL and were scored clinically as asymptomatic if they had total scores of 0 to 4 and as symptomatic if they had scores greater than 4 [8].

\section{MAPIA strip preparation}

Antigens were sprayed onto a $0.45-\mu \mathrm{m}$, pore-size nitrocellulose membrane (HiFlow Plus HFB24004, Millipore, MA) in parallel bands via use of a semi-automatic air-brush printing device (CAMAG automatic TLC sample 4, CAMAG, Muttenz, Switzerland) with a volume of $5 \mu \mathrm{L} /$ $\mathrm{mm}$. As described by Lyashchenko and collaborators [20], each antigen solution was printed in $15 \mathrm{~cm}$ length lines using the concentration of antigen according to solubility in phosphate-buffered saline (PBS): Lci1 $=0.236 \mathrm{mg} / \mathrm{mL}$, Lci2 $=0.222 \mathrm{mg} / \mathrm{mL}, \mathrm{Lci} 3=0.530 \mathrm{mg} / \mathrm{mL}, \mathrm{Lci} 4=0.055$ $\mathrm{mg} / \mathrm{mL}, \mathrm{Lci} 5=0.139 \mathrm{mg} / \mathrm{mL}$, Lci6 $=0.347 \mathrm{mg} / \mathrm{mL}$, Lci7 $=$ $0.097 \mathrm{mg} / \mathrm{mL}$, Lci8 $=0.125 \mathrm{mg} / \mathrm{mL}, \mathrm{Lci} 10=0.139 \mathrm{mg} / \mathrm{mL}$, Lci11 $=0.055 \mathrm{mg} / \mathrm{mL}$, Lci12 $=0.236 \mathrm{mg} / \mathrm{mL}$, Lci13 $=$ $0.180 \mathrm{mg} / \mathrm{mL}$. Three additional lines were saturated with L. major lysate $=0.7620 \mathrm{mg} / \mathrm{mL}$, recombinant CRA\&FRA T. cruzi proteins $=0.290 \mathrm{mg} / \mathrm{mL}$, and a protein A solution = $0.200 \mathrm{mg} / \mathrm{mL}$. The printed nitrocellulose membranes were dried in ambient air and cut into 5 -mm strips.

\section{Serum incubation and antibody detection}

Before incubation with test sera, strips were blocked for $1 \mathrm{~h}$ in $800 \mu \mathrm{l}$ of PBS with $0.3 \%$ Tween 20 (Calbiochem, La Jolla, CA) and 5\% instant nonfat dry milk at room temperature while rocking. Then, the strips were incubated with 1:100 dilution of each serum for $30 \mathrm{~min}$ at room temperature while rocking. After being triplewashed with $\mathrm{PBS}$-Tween under agitation for $5 \mathrm{~min}$ at $37^{\circ} \mathrm{C}$, the strips were incubated with $1 \mathrm{~mL}$ of goat anti$\operatorname{dog}$ IgG antibodies conjugated with peroxidase (1:150 dilution), at room temperature for $1 \mathrm{~h}$, and then washed twice. Enzyme activity was visualized by incubating the strips for 5 min with $1 \mathrm{~mL}$ of substrate-chromogenic solution $(5 \mathrm{mg}$ of DAB in $19,995 \mu \mathrm{L}$ of PBS, with $5 \mu \mathrm{L}$ of hydrogen peroxidase). To stop the reaction, the strips were rinsed extensively in distilled water at room temperature. The strips were then dried and immediately stored in dark conditions until the results were visually read and digitalized.

\section{Data analysis}

Test positivity was evaluated by interpretation of serum antibody reactivity by visual detection of a brown band on the antigen-impregnated nitrocellulose strips. Epi Info 7 (CDC, Atlanta, Georgia - USA) was used to perform combinatorial analysis. 


\section{Ethical approval for animal use}

All experiments involving animals were performed in compliance with Brazilian federal law for animal experimentation (Law 11794). In conformity with the Oswaldo Cruz Foundation (FIOCRUZ) animal experimentation guidelines, and according to instructions outlined in the Brazilian Ministry of Health's manual for the surveillance and control of VL. The present study was approved by the Institutional Review Board (CEUA protocol no. 015/ 2009) of the Gonçalo Moniz Research Center in Bahia, Brazil (CPqGM-FIOCRUZ/BA).

\section{Finding}

All MAPIA procedures were optimized with regard to antigen concentrations and serum dilution (data not shown). A total of 138 sera from clinically symptomatic $(\mathrm{n}=41)$ and asymptomatic $(\mathrm{n}=16)$ L. infantum-infected dogs, healthy controls $(n=40)$ and animals harboring other infections $(n=40)$ were tested against the selected panel of 12 antigens. The results showed variable antigen recognition patterns among the evaluated serum samples, as indicated in Figure 1. As shown in Table 1, the individual sensitivities of the 12 recombinant proteins coated onto nitrocellulose membranes ranged from 4 to $58 \%$ for identifying parasite-positive dogs. Nonetheless, each of the antigens detected some positive sera that others missed. When the individual recombinant proteins were combined, the total sensitivity increased to
$81 \%$ (Figure 2), revealing that the antigens complemented each other. The well-known heterogeneous humoral immune response that develops in L. infantum-infected dogs [24] likely involves multiple antigens that are differentially recognized by the serum of each animal depending on the state of disease [8]. Therefore, further research into the development of a more reliable rapid test based on the combination of multiple antigens in a DPP format should be pursued.

Efforts to develop a diagnostic test based on antibodydetection for VL or CVL have been underway for decades although few of such tests are chromatographic immunoassays currently used in endemic countries $[12,13,25]$. Prior studies have demonstrated that antibodies against these antigens are mainly detectable in cases with advanced stages of disease, while they are much less detectable in sera from asymptomatic cases $[12,13]$. Variable multi-antigen recognition by canine serum provides an explanation for the variable performance of commercial tests for detecting infected dogs. Here, we found the recombinant antigens evaluated were more sensitive in symptomatic cases $(89 \%)$ in comparison to dogs without signs of VL (56\%), thus confirming that these antigens are differentially recognized at different stages of infection. Using MAPIA, the Lci2B and Lci1A antigens gave the best results in terms of sensitivity (76\% and $71 \%$, respectively) for the detection of dogs with active disease. Although individually, none of these

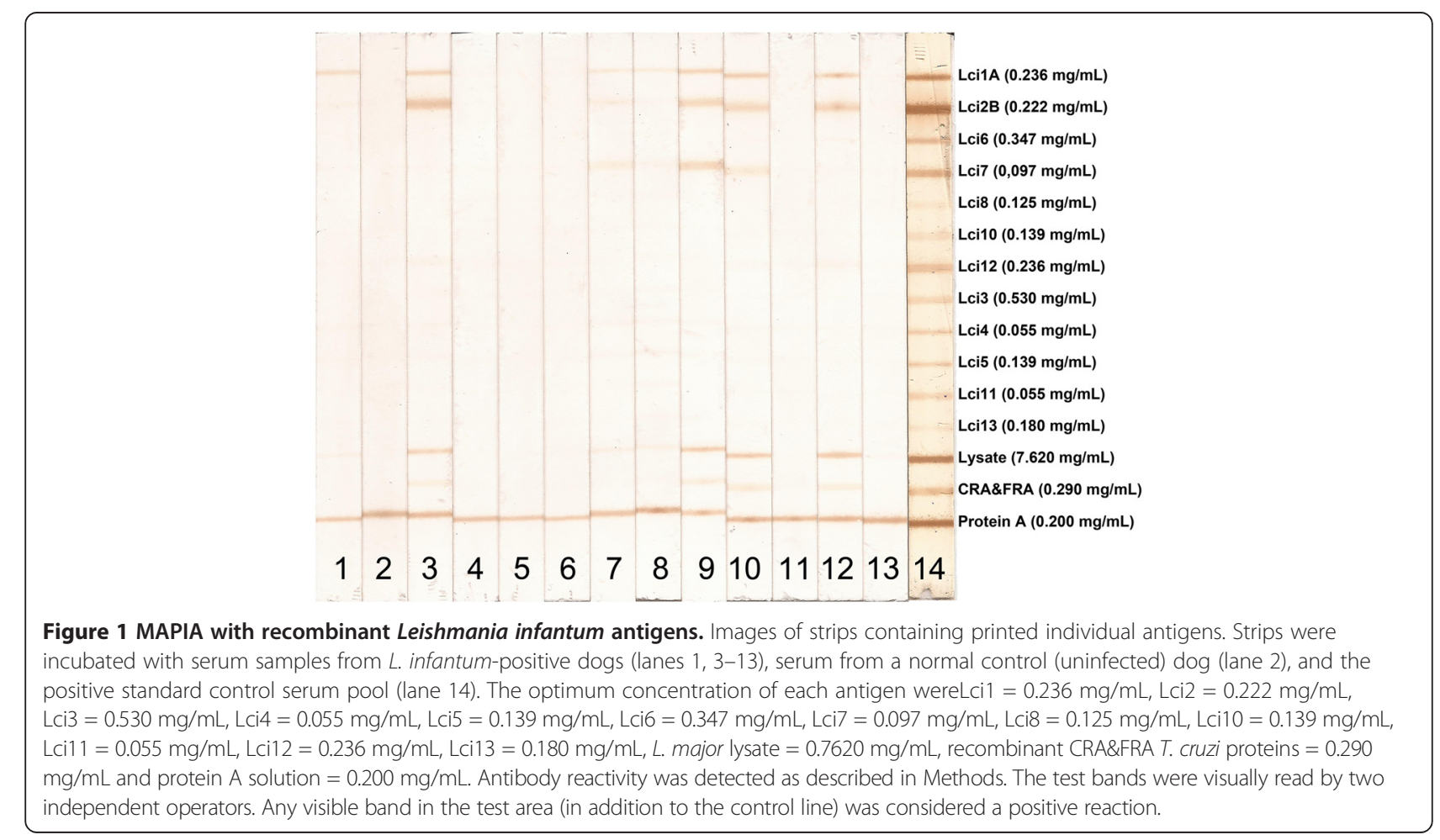


Table 1 Sensitivity and specificity of MAPIA with recombinant antigens of Leishmania infantum for the serodiagnosis of canine visceral leishmaniasis

\begin{tabular}{|c|c|c|c|c|c|c|c|c|c|c|c|c|c|}
\hline \multirow[t]{2}{*}{ Study groups (n) } & \multicolumn{13}{|c|}{ Reactivity with individual $L$. infantum antigens (number of positive sera) } \\
\hline & Lci1A & Lci2B & Lci3 & Lci4 & Lci5 & Lci6 & Lci7 & Lci8 & Lci10 & Lci11 & Lci12 & Lci13 & Any antigen \\
\hline Dogs without signs of VL (16) & 3 & 2 & 4 & 6 & 4 & 1 & 2 & 1 & 4 & 2 & 6 & 1 & 9 \\
\hline Dogs with signs of VL (41) & 29 & 31 & 8 & 15 & 15 & 1 & 9 & 4 & 3 & 8 & 13 & 3 & 37 \\
\hline Total (57) & 32 & 33 & 12 & 21 & 19 & 2 & 11 & 5 & 7 & 10 & 19 & 4 & 46 \\
\hline \% Sensitivity & 56 & 58 & 21 & 37 & 33 & 4 & 19 & 9 & 12 & 18 & 33 & 7 & 81 \\
\hline Normal control (40) & 0 & 1 & 2 & 2 & 2 & 1 & 3 & 1 & 2 & 2 & 4 & 3 & 6 \\
\hline Dermal leishmaniasis* (10) & 6 & 3 & 0 & 2 & 2 & 0 & 1 & 0 & 0 & 0 & 0 & 0 & 6 \\
\hline Trypanosomiasis* (10) & 1 & 1 & 1 & 1 & 1 & 0 & 1 & 0 & 1 & 0 & 3 & 0 & 3 \\
\hline Babesiosis* (10) & 1 & 2 & 3 & 3 & 3 & 0 & 1 & 0 & 3 & 1 & 2 & 2 & 4 \\
\hline Ehrlichiosis* (11) & 0 & 0 & 0 & 1 & 1 & 0 & 1 & 0 & 1 & 0 & 1 & 1 & 2 \\
\hline Total (81) & 8 & 7 & 7 & 11 & 9 & 1 & 7 & 1 & 7 & 3 & 10 & 6 & 21 \\
\hline \% Specificity & 90 & 91 & 91 & 86 & 89 & 99 & 91 & 99 & 91 & 96 & 88 & 93 & 74 \\
\hline
\end{tabular}

*Sera of dogs affected with other infections.

antigens performed well in detecting asymptomatic dogs (sensitivity ranging from 6 to 38\%), 46 out of 57 serum samples recognized two groups of combined antigens (namely, rLci1A, rLci2B, rLci8, rLci12 and rLci4 or rLci1A, rLci2B, rLci8, rLci12 and rLci5), thus improving the overall sensitivity of the test to $81 \%$. This result is in agreement with previously published results suggesting that more than one recombinant antigen may be useful to maximize the sensitivity of diagnostic tests for CVL $[22,26]$.

As shown in Table 1, the individual antigens displayed variable specificities (ranging from $86 \%$ to $99 \%$ ). The rLci1A antigen had a specificity of $90 \%$ and the rLci2B

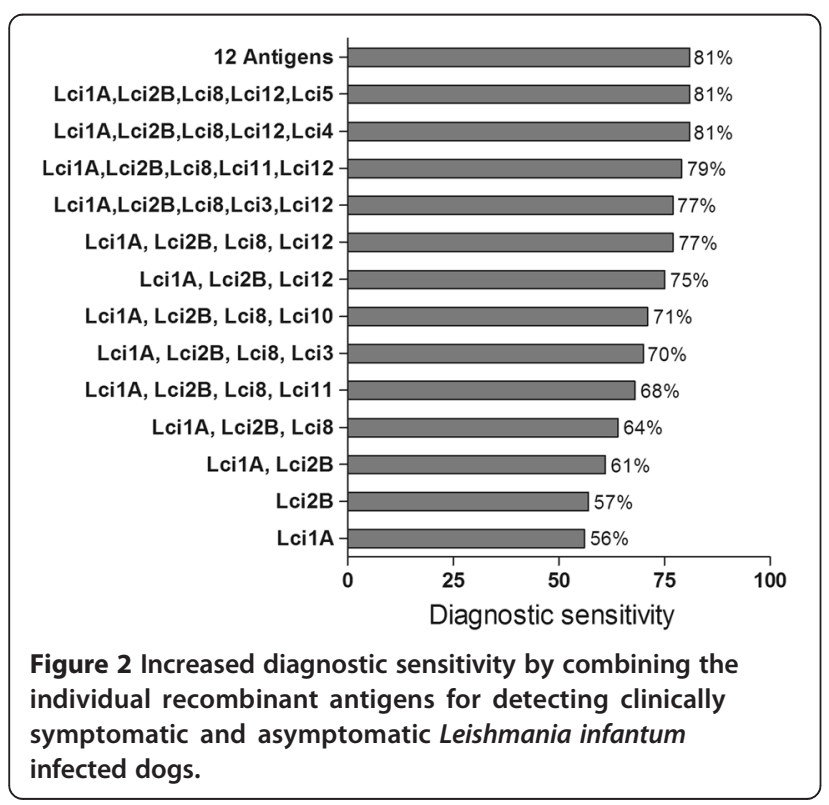

antigen had a specificity of $91 \%$. These results are in accordance with previous study, which reported specificity values of $92 \%$ for rLci1A and 95\% for rLci2B [27]. In addition, rLci8, which composes the groups of combined antigens, also showed a very high specificity value (99\%). By contrast, the other three antigens, rLci4, rLci12 and rLci5, included in at least one of the two groups of combined antigens, showed lower specificity values of, respectively, 86,88 and $89 \%$, reducing overall specificity value to $74 \%$ (Table 1 ).

MAPIA has previously proven to facilitate rapid screening of antigens, since in comparison to ELISA [20], it is an easy and rapid test that simultaneously detects the response of sera to multiple antigens coated onto a single nitrocellulose strip. Indeed, the serological performance of antigens in MAPIA shown to be a good predictor of their performance in several point-of-care assays $[14,15,28]$. Here, we reveal MAPIA to be a useful tool for L. infantum antigen selection for the future development of an immunodiagnostic test for CVL. This screening test allowed the selection of two sets of antigens (rLci1A, rLci2B, rLci8, rLci12 and rLci4 or rLci1A, rLci2B, rLci8, rLci12 and rLci5) offering both high sensitivity and specificity; our results illustrate the benefit of utilizing a more effective multi-antigen point-of-care test in DPP format for application in mass assessment surveys of $L$. infantum-exposed dogs.

\section{Competing interests}

The authors declare that they have no competing interests.

Authors' contributions

Conceived and designed the experiments: EDS, GG Jr, DBMF, PSTV.

Performed the experiments: IQO, RAS, MVS. Analyzed the data: GG Jr, DBMF, PSTV. Contributed reagents/materials/analysis tools: ABR. All authors read and approved the final version of the manuscript. 


\section{Acknowledgments}

This work was supported by INCT-DT, FAPESB, and FIOCRUZ. The authors would like to thank Dr. Flávia W. Cruz McBride for support to obtain negative control samples in Pelotas. We are also grateful to Andris K. Walter for providing English revision and consulting services. In addition, this manuscript has been edited by native English-speaking experts from BioMed Proofreading LLC.

\section{Author details}

'Laboratório de Patologia e Biointervenção, Centro de Pesquisas Gonçalo Moniz, FIOCRUZ, Rua Waldemar Falcão, 121 (Candeal), Salvador, BA, Brazil. ${ }^{2}$ Laboratório de Tecnologia Diagnóstica, Instituto de Tecnologia em Imunobiológicos, Bio-Manguinhos, FIOCRUZ, Rio de Janeiro, RJ, Brazil. ${ }^{3}$ Instituto de Ciência e Tecnologia de Doenças Tropicais, INCT-DT, Salvador, BA, Brazil. ${ }^{4}$ Laboratório de Imunopatologia, Núcleo de Pesquisas em Ciências Biológicas, Universidade Federal de Ouro Preto, Ouro Preto, MG, Brazil. ${ }^{5}$ Departamento de Medicina Veterinária Preventiva e Produção Animal, Escola de Medicina Veterinária e Zootecnia, Universidade Federal da Bahia, Salvador, BA, Brazil.

Received: 8 September 2014 Accepted: 11 January 2015

Published online: 24 January 2015

\section{References}

1. Alvar J, Velez ID, Bern C, Herrero M, Desjeux P, Cano J, et al. Leishmaniasis worldwide and global estimates of its incidence. PLoS One. 2012;7(5):e35671.

2. Quinnell RJ, Courtenay O. Transmission, reservoir hosts and control of zoonotic visceral leishmaniasis. Parasitology. 2009;136(14):1915-34.

3. Ashford DA, David JR, Freire M, David R, Sherlock I, Eulalio MC, et al. Studies on control of visceral leishmaniasis: impact of dog control on canine and human visceral leishmaniasis in Jacobina, Bahia. Brazil Am J Trop Med Hyg. 1998:59(1):53-7.

4. Moreira Jr ED, Mendes de Souza VM, Sreenivasan M, Nascimento EG, Pontes de Carvalho L. Assessment of an optimized dog-culling program in the dynamics of canine Leishmania transmission. Vet Parasitol. 2004;122(4):245-52

5. Aisa MJ, Castillejo S, Gallego M, Fisa R, Riera MC, de Colmenares M, et al. Diagnostic potential of Western blot analysis of sera from dogs with leishmaniasis in endemic areas and significance of the pattern. Am J Trop Med Hyg. 1998;58(2):154-9.

6. Alvar J, Molina R, San Andres M, Tesouro M, Nieto J, Vitutia M, et al. Canine leishmaniasis: clinical, parasitological and entomological follow-up after chemotherapy. Ann Trop Med Parasitol. 1994;88(4):371-8.

7. Falqueto A, Ferreira AL, dos Santos CB, Porrozzi R, da Costa MV, Teva A, et al. Cross-sectional and longitudinal epidemiologic surveys of human and canine Leishmania infantum visceral infections in an endemic rural area of southeast Brazil (Pancas, Espirito Santo). Am J Trop Med Hyg. 2009;80(4):559-65.

8. Quinnell RJ, Courtenay O, Davidson S, Garcez L, Lambson B, Ramos P, et al. Detection of Leishmania infantum by PCR, serology and cellular immune response in a cohort study of Brazilian dogs. Parasitology. 2001;122(Pt 3):253-61.

9. Reithinger R, Quinnell RJ, Alexander B, Davies CR. Rapid detection of Leishmania infantum infection in dogs: comparative study using an immunochromatographic dipstick test, enzyme-linked immunosorbent assay, and PCR. J Clin Microbiol. 2002:40(7):2352-6.

10. Dye C, Vidor E, Dereure J. Serological diagnosis of leishmaniasis: on detecting infection as well as disease. Epidemiol Infect. 1993;110(3):647-56

11. Lombardo G, Pennisi MG, Lupo T, Chicharro C, Solano-Gallego L. Papular dermatitis due to Leishmania infantum infection in seventeen dogs: diagnostic features, extent of the infection and treatment outcome. Parasit Vectors. 2014;7:120.

12. da Costa RT, Franca JC, Mayrink W, Nascimento E, Genaro O, Campos-Neto A. Standardization of a rapid immunochromatographic test with the recombinant antigens K39 and K26 for the diagnosis of canine visceral leishmaniasis. Trans R Soc Trop Med Hyg. 2003;97(6):678-82

13. Grimaldi Jr $G$, Teva A, Ferreira AL, dos Santos CB, Pinto I, De-Azevedo CT, et al. Evaluation of a novel chromatographic immunoassay based on DualPath Platform technology (DPP(R) CVL rapid test) for the serodiagnosis of canine visceral leishmaniasis. Trans R Soc Trop Med Hyg. 2012;106(1):54-9.

14. Lyashchenko KP, Greenwald R, Esfandiari J, Chambers MA, Vicente J, Gortazar C, et al. Animal-side serologic assay for rapid detection of Mycobacterium bovis infection in multiple species of free-ranging wildlife. Vet Microbiol. 2008;132(3-4):283-92.
15. Lyashchenko KP, Greenwald R, Esfandiari J, Meylan M, Burri IH, Zanolari P. Antibody responses in New World camelids with tuberculosis caused by Mycobacterium microti. Vet Microbiol. 2007;125(3-4):265-73.

16. Boarino A, Scalone A, Gradoni L, Ferroglio E, Vitale F, Zanatta R, et al. Development of recombinant chimeric antigen expressing immunodominant B epitopes of Leishmania infantum for serodiagnosis of visceral leishmaniasis. Clin Diagn Lab Immunol. 2005;12(5):647-53.

17. Costa MM, Penido M, dos Santos MS, Doro D, de Freitas E, Michalick MS, et al. Improved canine and human visceral leishmaniasis immunodiagnosis using combinations of synthetic peptides in enzyme-linked immunosorbent assay. PLoS Negl Trop Dis. 2012;6(5):e1622.

18. Passos S, Carvalho LP, Orge G, Jeronimo SM, Bezerra G, Soto M, et al. Recombinant Leishmania antigens for serodiagnosis of visceral leishmaniasis. Clin Diagn Lab Immunol. 2005;12(10):1164-7.

19. Rosati S, Ortoffi M, Profiti M, Mannelli A, Mignone W, Bollo E, et al. Prokaryotic expression and antigenic characterization of three recombinant Leishmania antigens for serological diagnosis of canine leishmaniasis. Clin Diagn Lab Immunol. 2003;10(6):1153-6.

20. Lyashchenko KP, Singh M, Colangeli R, Gennaro ML. A multi-antigen print immunoassay for the development of serological diagnosis of infectious diseases. J Immunol Methods. 2000;242(1-2):91-100.

21. Oliveira GG, Magalhaes FB, Teixeira MC, Pereira AM, Pinheiro CG, Santos LR, et al. Characterization of novel Leishmania infantum recombinant proteins encoded by genes from five families with distinct capacities for serodiagnosis of canine and human visceral leishmaniasis. Am J Trop Med Hyg. 2011;85(6):1025-34

22. Teixeira MC, Oliveira GG, Silvany MA, Alcantara-Neves NM, Soares MB, Ribeiro-Dos-Santos $\mathrm{R}$, et al. A strategy for identifying serodiagnostically relevant antigens of Leishmania or other pathogens in genetic libraries. Biologicals. 2007;35(1):51-4.

23. Solca Mda S, Guedes CE, Nascimento EG, Oliveira GG, dos Santos WL, Fraga $\mathrm{DB}$, et al. Qualitative and quantitative polymerase chain reaction (PCR) for detection of Leishmania in spleen samples from naturally infected dogs. Vet Parasitol. 2012;184(2-4):133-40.

24. Solano-Gallego L, Riera C, Roura X, Iniesta L, Gallego M, Valladares JE, et al. Leishmania infantum-specific lgG, IgG1 and $\lg G 2$ antibody responses in healthy and ill dogs from endemic areas. Evolution in the course of infection and after treatment. Vet Parasitol. 2001;96(4):265-76.

25. Mettler M, Grimm F, Capelli G, Camp H, Deplazes P. Evaluation of enzymelinked immunosorbent assays, an immunofluorescent-antibody test, and two rapid tests (immunochromatographic-dipstick and gel tests) for serological diagnosis of symptomatic and asymptomatic Leishmania infections in dogs. J Clin Microbiol. 2005;43(11):5515-9.

26. Lyashchenko KP, Greenwald R, Esfandiari J, Greenwald D, Nacy CA, Gibson S, et al. PrimaTB STAT-PAK assay, a novel, rapid lateral-flow test for tuberculosis in nonhuman primates. Clin Vaccine Immunol. 2007;14(9):1158-64.

27. de Souza CM, Silva ED, Ano Bom AP, Bastos RC, Nascimento HJ, da Silva Junior JG. Evaluation of an ELISA for canine leishmaniasis immunodiagnostic using recombinant proteins. Parasite Immunol. 2012;34(1):1-7.

28. Buddle BM, Wilson T, Denis M, Greenwald R, Esfandiari J, Lyashchenko KP, et al. Sensitivity, specificity, and confounding factors of novel serological tests used for the rapid diagnosis of bovine tuberculosis in farmed red deer (Cervus elaphus). Clin Vaccine Immunol. 2010;17(4):626-30.

\section{Submit your next manuscript to BioMed Central and take full advantage of:}

- Convenient online submission

- Thorough peer review

- No space constraints or color figure charges

- Immediate publication on acceptance

- Inclusion in PubMed, CAS, Scopus and Google Scholar

- Research which is freely available for redistribution 